Check for updates

Cite this: Sustainable Energy Fuels, 2019, 3, 1693

Received 10th December 2018 Accepted 26th March 2019

DOI: $10.1039 / \mathrm{c} 8 \mathrm{se} 00610 \mathrm{e}$

rsc.li/sustainable-energy

\section{Nuclear fuel cycle, with a liquid ore and fuel: toward renewable energy}

\author{
Claude A. Degueldre, (D) * Richard J. Dawson and Vesna Najdanovic-Visak
}

To fulfill the conditions required for a nuclear renewable energy concept, one has to explore a combination of processes going from the front end of the nuclear fuel cycle to the fuel production and the energy conversion using specific fluid fuels and reactors. Extraction of uranium from a diluted fluid ore such as seawater has been studied in various countries worldwide. This extraction should be carried out parsimoniously. An extraction rate of $10^{3}$ tons of $U$ per year over centuries would not modify significantly the equilibrium concentration of uranium in the oceans (3.3 ppb). This equilibrium results from the input of $10^{4}$ tons of $U$ per year by river waters and its scavenging on the sea floor from the $1.37 \times 10^{18}$ tons of water in the oceans. For a renewable uranium extraction, the use of a specific biomass material is suggested to adsorb uranium and subsequently other transition metals. The uranium loading on the biomass would be around $100 \mathrm{mg}$ per $\mathrm{kg}$. After contact time, the loaded material would be dried and burned $\left(\mathrm{CO}_{2}\right.$ neutral) with heat conversion into electricity. The uranium 'burning' in a molten salt fast reactor helps to optimize the energy conversion by burning all actinide isotopes with an excellent yield for producing a maximum amount of thermal energy from fission and converting it into electricity. This optimisation can be reached by reducing the moderation and the fission product concentration in the liquid fuel/coolant. These effects can be achieved by using a maximum amount of actinides and a minimum amount of alkaline/earth alkaline elements yielding a harder neutron spectrum. Under these optimal conditions the consumption of natural uranium would be 7 tons per year and per gigawatt (GW) of produced electricity. The coupling of uranium extraction from the sea and its optimal utilisation in a molten salt fast reactor should allow nuclear energy to gain the label renewable. In addition, the amount of seawater used by a nuclear power plant to cool the last coolant fluid and the turbine would be $\sim 2.1 \times 10^{9}$ tons per year for a fast molten salt reactor, corresponding to 7 tons of natural uranium extractable per year. This practice justifies the label renewable.

\section{Introduction}

Nuclear fuel is traditionally obtained by extracting uranium from solid ores mined from uranium deposits or from rather uranium rich rocks. After extraction, concentration and specific solid fuel preparation, the fuel is 'burnt' in reactors for the production of heat and electricity. This mode of extraction of uranium is not renewable and current consumption levels indicate that the reserves in current mines will be depleted in 20 years (ref. 1) and all known economic reserves will be consumed in 80 years (ref. 2).

Presently, nuclear fuel production is mainly driven by uranium mining from relatively rich deposits. The uranium extraction is, however, limited to approximately $100 \mathrm{ppm}$ due to economic reasons as estimated using Mudd data. ${ }^{3}$ In reality, extraction may be carried out from less concentrated sources when their decontamination is required e.g. phosphates, or

Engineering Department, Lancaster University, Lancaster LA1 4YW, UK. E-mail: c. degueldre@lancaster.ac.uk when the production of uranium oxide can be performed at very low costs. For a country like UK which imports all of its uranium from abroad with shipping distances of about $6000 \mathrm{~km}$ or more (e.g. Canada and Niger) the extraction of $\mathrm{U}$ from seawater should be the first priority.

It should also be noted that several radiotoxic isotopes are released during conventional uranium extraction from solid ores e.g. radon emanations and tailings. The protocol suggested here concerns seawater, a fluid in which the decay products are not retained.

Uranium extraction from seawater has been researched for approximately 30 years in Japan, focusing on amidoxime-based sorbents ${ }^{4,5}$ and recycling of the absorbent by desorption. Similar approaches have recently re-emerged in other countries, e.g. the $\mathrm{USA}^{6}{ }^{6}$ coupling sorption and electrochemical separation and even now in China ${ }^{7}$ mainly due to its strategic importance. Today the specific uranium sorption on amidoxime is well understood. ${ }^{8}$ The extraction of uranium from seawater is, however, limited by several criteria (e.g. strategy, costs, legal aspects, and ecological requirements) as recently discussed. ${ }^{9}$ 
This study explores the potential extraction of uranium from seawater using a versatile chemical approach based on combined chemisorption ${ }^{10}$ and potential reduction (as modelled earlier for neptunium ${ }^{11}$ ) onto an organic/bioorganic waste material.

After collection of the uranium loaded biomaterial, the wet phase must be dried and burnt (producing heat that can be converted into electricity). Uranium can then be extracted from the ashes following the classical hydrometallurgical route. It can finally be used in a fuel form in dedicated reactors.

Molten Salt Reactors (MSR) are liquid fuel reactors where, in the classical concept, the fuel is also the coolant. The use of molten salt reactors for example as a Small Modular Reactor (SMR) is suggested, together with optimisation of neutron economy and fissile materials management in the nuclear fuel cycle. The design of a SM-MS reactor deals with key questions such as: (i) how can one optimise the reactor design for flexible and transient utilisation? (ii) How can one upgrade the neutron economy? With the solubility increase of $\mathrm{Xe}$ and $\mathrm{Kr}$ in the $\mathrm{M}$ $\mathrm{U}-{ }^{37} \mathrm{Cl}$ (M: Na, K, Rb, Mg etc.) molten phase during temperature increase, the neutron economy is degraded because of the presence of strong neutron absorbers such as ${ }^{135} \mathrm{Xe}$. Some experimental and modelling research studies are still needed on the solubility of $\mathrm{Kr}$, Xe and I, the Xe precursor, in molten salts.

The present study evaluates the potential of combining uranium extraction from seawater and its use in a liquid fuel reactor to make nuclear energy renewable.

\section{Extraction of uranium from seawater on biowaste materials}

A better economical and ecological way of extracting uranium from seawater by optimising the extraction process by studying surface complexation and its reduction on solid organic ligands is first required. The process has to be studied in a comprehensive and systematic way to provide key information on potential extraction routes from seawater. As the use of seawater is difficult at the ton level, a strategy is suggested using laboratory tests prior to on site tests in the final step. This extraction is a key issue for the scientists involved in achieving a sustainable nuclear fuel cycle with a renewable approach.

Uranium extraction from seawater becomes renewable when the extraction rate does not exceed the input rate from rivers (i.e. $10^{4}$ tons of soluble $\mathrm{U}$ per year (ref. 12)). Actually, if $\mathrm{U}$ is not extracted, it is discarded from the seawater by scavenging (sedimentation) on the seafloor and ultimately eliminated by subduction of the pelagic sediment layer in the Earth's mantle. In addition, since the volume of water in the sea is extremely large the extraction over the next 1000 years would not be significant compared to the total amount e.g. $\sim 10^{12} \mathrm{~kg}$. During extraction, the environmental flora and fauna need to be protected with respect to possible speciation changes of redox sensitive elements or dissolved traces from the sorbing phase; however, it could be anticipated that a careful extraction of $U$ should not modify the natural environment.

The proposed extraction strategy using low cost bioorganic waste such as coffee-, black tea- and brewery-residues, seeds, fruit peels, juice waste, tree bark, straw, wheat bran etc. (as delivered or treated) as sorbents needs to be tested. The process would subsequently include burning of the dried sorbed material followed by extraction of $U$ from the ashes such as in the case of $\mathrm{U}$ recovery from coal. ${ }^{13} \mathrm{~A}$ similar approach is followed for wastewater treatment. ${ }^{14}$

The thermodynamic modelling of the uranium surface complexes is performed using correlation methods ${ }^{15}$ applied to the reactions:

$$
\begin{gathered}
\text { So-H }+\mathrm{UO}_{2}^{2+} \Leftrightarrow>\mathrm{So}^{2+} \mathrm{UO}_{2}^{+}+\mathrm{H}^{+} \\
+4 \mathrm{H}^{+}+2 \mathrm{e}^{-} \Uparrow 2 \mathrm{H}_{2} \mathrm{O}+\boldsymbol{\square}+4 \mathrm{H}^{+}+2 \mathrm{e}^{-} \Uparrow 2 \mathrm{H}_{2} \mathrm{O}+ \\
\text { So-H }+\mathrm{U}^{4+} \Leftrightarrow>\mathrm{So}^{2} \mathrm{U}^{3+}+\mathrm{H}^{+}
\end{gathered}
$$

and

$$
\begin{aligned}
& \text { So-H } \left.+\left[\mathrm{UO}_{2}\left(\mathrm{CO}_{3}\right)_{i}\right]^{(2-2 i)+} \Leftrightarrow>\mathrm{So}-\mathrm{UO}_{2}\left(\mathrm{CO}_{3}\right)_{i}\right]^{(1-2 i)+}+\mathrm{H}^{+} \\
& +4 \mathrm{H}^{+}+2 \mathrm{e}^{-} \Downarrow 2 \mathrm{H}_{2} \mathrm{O}+(i-j)\left(\mathrm{CO}_{3}\right)^{2-}+\mathbf{\square}+4 \mathrm{H}^{+}+2 \mathrm{e}^{-} \Uparrow 2 \mathrm{H}_{2} \mathrm{O}+(i-j)\left(\mathrm{CO}_{3}\right)^{2-}+ \\
& \text { So-H } \left.+\left[\mathrm{U}\left(\mathrm{CO}_{3}\right)_{j}\right]^{(4-2 j)+} \Leftrightarrow>\mathrm{So}-\mathrm{U}\left(\mathrm{CO}_{3}\right)_{j}\right]^{(3-2 j)+}+\mathrm{H}^{+}
\end{aligned}
$$

where $>$ So-H stands for the sorbing groups and $\mathbf{D}$ displays the equation separation. The modelling of the thermodynamic properties of the sorbents and uranium in seawater using a dedicated thermodynamic approach is carried out to estimate if coupling of sorption and redox reaction takes place during the absorption process.

Presently, the formation of $\mathrm{U}$ aqueous complexes shall impact on their sorption onto the active groups $(-\mathrm{So}-\mathrm{H})$. The complex properties are affected by water temperature $\left(T_{10-20^{\circ} \mathrm{C}}\right)$, pressure (1 bar), water acidity ( $\mathrm{pH}$ around 8) and an ionic strength of $0.3 \mathrm{M}$. Sorbing functional groups are given in Table $1 .^{16}$ The species concentrations based on the element composition of seawater are given by calculated output results using thermodynamic data from Ball \& Nordstrom, 1991. ${ }^{17}$ The tricarbonate complex concentration is $1.25 \times 10^{-8} \mathrm{M}$, and the bicarbonate complex is $1.81 \times 10^{-9} \mathrm{M}$. All other species are well below $1.00 \times 10^{-10} \mathrm{M}$.

A relationship between a metal's sorption coefficient and its complexation in solution has been derived, e.g. Degueldre et al. (1994), ${ }^{15}$ using surface complexation properties. The surface complexation constants may be evaluated on the basis of their correlation for each complex form with the hydroxo-complex formation constants. The impact of the

Table 1 Sorbing groups adapted from ref. 16

\begin{tabular}{lll}
\hline Nomenclature & Group name & $\begin{array}{l}\text { Sorbing group } \\
\text { formula }\end{array}$ \\
\hline So-H & Carboxylic & $\mathrm{R}-\mathrm{CO}-\mathrm{OH}$ \\
& Alcohol or phenol & $\mathrm{R}-\mathrm{OH}$ \\
& Thiol or thiophenol & $\mathrm{R}-\mathrm{SH}$ \\
& Hydroxyl amine & $\mathrm{R}_{2} \mathrm{~N}-\mathrm{OH}$ \\
$>\mathrm{So}<\mathrm{H}_{n}$ & Amine or & $\mathrm{R}-\mathrm{NH}_{2}$ \\
& aminophenol & \\
& Amide & $\mathrm{R}-\mathrm{CO}-\mathrm{NH} \mathrm{H}_{2}$ \\
& Amidoxime & $\mathrm{R}-\mathrm{C}(=\mathrm{NOH})-\mathrm{NH}_{2}$
\end{tabular}


redox is then evaluated using the Nernst equation considering surface complexation for all redox species e.g. see Degueldre (1997). ${ }^{11}$

In seawater (oxidative conditions) $\mathrm{U}(\mathrm{vI})$ should only be formed; its reduction would yield $\mathrm{U}(\mathrm{v})$ and $\mathrm{U}(\mathrm{Iv})$. Reaction on specific substrates may stabilise one form versus another favouring sorption. The kinetics of these uranium species formation are also linked to the concentration of the species.

Uranium sorption from freshwater sources onto Citrus limetta peels $^{18}$ and citrus reprocessing waste ${ }^{19}$ has been reported recently. With regard to the extraction of uranium from seawater, Chlorella dry cells and orange peels adsorb a great quantity of uranium; in contrast, some natural high polymers such as chitin, chitosan, cellulose and starch do not absorb uranium significantly from seawater. Phosphorylated polysaccharides (chitin phosphate, chitosan phosphate and cellulose phosphate) and acid polysaccharides (alginic acid and pectic acid) have also been found to strongly sorb uranium. The absorption of uranium by chitin phosphate as reported is rapid during the first 3 hours. It was observed that chitosan phosphate can recover uranium $(2.6 \mu \mathrm{g}$ per g adsorbent) from natural seawater. ${ }^{20}$ Among biological samples e.g. grasses, leaves, barks, roots and fruit bodies, Myrica cortex barks were found to be the most performing absorbents of $\mathrm{U}$ in seawater with $>30 \%$ uranium absorbed. ${ }^{21}$

Clearly, uranyl sorption on a colloidal material should combine surface complexation, reduction and colloid aggregation/precipitation to be efficient.

Polyphenols are reported to be very efficient for extraction because of their strong complexation potential (see Fig. 1) and because of their antioxidant properties and their peptisation/ flocculation potential. ${ }^{22}$ Quercetin, a widely found polyphenol e.g. in citrus fruits, wine tannin, etc., combines these complexation (Fig. 1a) and bridging properties (Fig. 1b) enhancing the extraction. These biomaterials are loaded within tannin which is mostly composed of polyphenols. The family of tanninloaded biomaterials is being further investigated, by testing berries, barks, malt and tealeaf biomasses. A uranium loading on the biomass would be around $100 \mathrm{mg}$ per $\mathrm{kg}$.

After collection of the uranium loaded biomaterial, the wet phase must be dried, prior to burning in a green and clean way as suggested by Ashworth et al. (2013). ${ }^{23}$ Uranium can then be extracted from the ashes following the classical hydrometallurgical route.

\section{Burning uranium in molten salt fast reactors}

Molten salt reactors (MSR) are liquid fuel reactors in which, in the classical concept, the fuel is also the coolant. ${ }^{24}$ To run the reactor in low consumption mode, the MSR must consume a minimum amount of uranium for producing a maximum amount of thermal energy and hence electrical energy. To achieve this conversion in an optimal way, a strict neutron economy is required, achieved by using the actinide isotopes in an efficient way favoring fission instead of capture. This may be performed using fast neutrons. However, since the neutron spectra are never fully fast but include also epithermal and thermal components, some of the actinide isotopes called fertile isotopes undergo neutron capture up to the formation of fissile isotopes e.g. ${ }^{239} \mathrm{Pu},{ }^{241} \mathrm{Pu},{ }^{242} \mathrm{Am}$, etc.

Even in a fast MSR the neutron spectrum is a mix of fast, epithermal and thermal. Consequently, the following reactions occur:

$$
\begin{aligned}
& { }^{235} \mathrm{U}+{ }^{1} \mathrm{n} \Rightarrow{ }^{92} \mathrm{Kr}+{ }^{141} \mathrm{Ba}+3{ }^{1} \mathrm{n} \text { takes place in a MSTR } \\
& { }^{238} \mathrm{U}+{ }^{1} \mathrm{n} \Rightarrow{ }^{93} \mathrm{Kr}+{ }^{143} \mathrm{Ba}+3{ }^{1} \mathrm{n} \text { takes place in a MSFR }
\end{aligned}
$$

where MSTR and MSFR stand for Molten Salt Thermal and Fast Reactor respectively.

The thermal part of the spectrum allows transmutation of the fertile isotopes into fissile isotopes

$$
{ }^{238} \mathrm{U}+{ }^{1} \mathrm{n} \Rightarrow{ }^{239} \mathrm{U} \Rightarrow \beta^{-}+\bar{v}+{ }^{239} \mathrm{~Np} \Rightarrow \beta^{-}+\bar{v}+{ }^{239} \mathrm{Pu}
$$

that undergo fission:

$$
{ }^{239} \mathrm{Pu}+{ }^{1} \mathrm{n} \Rightarrow{ }^{94} \mathrm{Rb}+{ }^{143} \mathrm{La}+3{ }^{1} \mathrm{n}
$$

During MSR operation, fission products are generated in the core of the reactor and in the primary loop. Some of them are strong poisons absorbing neutrons. The relative concentration of fission products follows the so called 'kamel' curve with the maxima located around $\mathrm{Zr}$ and Mo for the light, and around Xe, $\mathrm{Cs}, \mathrm{Ba}$ and La for the heavy fission products. Some of them are not sustainable isotopes such as ${ }^{135} \mathrm{Xe}$ (half-life $9.1 \mathrm{~h}$ ), with a neutron capture cross-section of $2 \times 10^{6}$ barns, or its parent nuclide ${ }^{135} \mathrm{I}$ with a half-life of $9.14 \mathrm{~h}$.

$$
{ }^{135} \mathrm{I} \Rightarrow \beta^{-}+\bar{v}+{ }^{135} \mathrm{Xe}(\uparrow) \Rightarrow \beta^{-}+\bar{v}+{ }^{135} \mathrm{Cs}
$$

They could be discarded from the core and loop by various strategies. A maximum elimination is required to optimise neutron economy. Once eliminated from the liquid fuel, they also need to be absorbed and fixed onto the absorber and embedded in waste matrices for disposition in a repository.

The behaviour and properties of $\mathrm{Kr}$, Xe and its precursor I in fluoride and chloride molten salts have been addressed by Smirnov et al. (1988). ${ }^{25}$ Actually, isotopes of Xe and $\mathrm{Kr}$ can act as neutron poisons that must be countered by a high fuel loading. For iodine the case is evident, ${ }^{135} \mathrm{I}$ decays into ${ }^{135} \mathrm{Xe}$, the stronger neutron absorber isotope. ${ }^{26}$ There are several strategies to eliminate an excess of ${ }^{135} \mathrm{Xe}$ such as the decay process, degassing and ventilation. The evolution of ${ }^{135} \mathrm{I}$ and ${ }^{135} \mathrm{Xe}$, which are entrained in the flowing salt, may be evaluated from their concentration change with the burn-up time. ${ }^{27}$ A fast circulation of the fuel salt could decrease the concentration of ${ }^{135} \mathrm{I}$ and ${ }^{135} \mathrm{Xe}$, and the reduction can achieve purging of around 50 and $40 \%$ of ${ }^{135} \mathrm{I}$ and ${ }^{135} \mathrm{Xe}$, respectively, at a small power level, e.g. $2 \mathrm{MW}$, when the core has the same fuel salt volume as that of the outer-loop. The second possibility is to use helium (less soluble) to remove the more soluble Xe. 

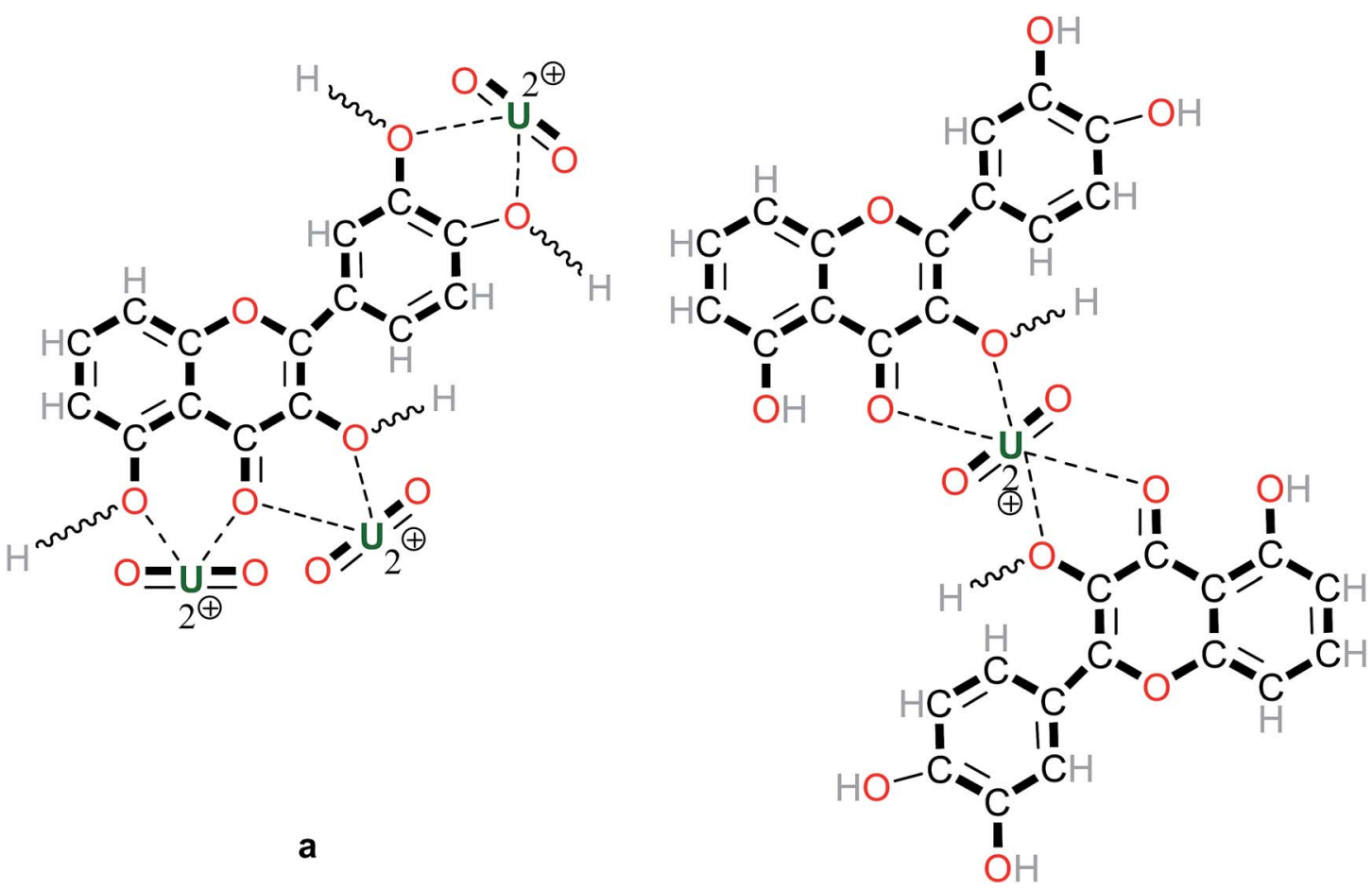

b

Fig. 1 Metal complex formation with polyphenols, example of the metal quercetin. (a) 3-1 and (b) 1-2 complexes, - coordination bond, H exchanged.

The analysis of the fission product volatilisation and sorption is carried out by mass spectroscopy which is more sensitive than that reported earlier e.g. ref. 28. These analyses are done in-line (contamination free). Presently, thermodynamic codes are used for the description of the dissolution of metals in aqueous solution and the elimination of volatile phases from fluids. ${ }^{29}$ The codes have been used to predict the solubility of volatile species from their molten salts. ${ }^{30}$ To understand the rate of degassing the coupling of codes (e.g. with the code 'fluent') is suggested to examine bubble formation and full removal e.g. ref. 31 .

The initial $\mathrm{UCl}_{4}$ can also be reduced to $\mathrm{UCl}_{3}$. The uranium redox buffer fixes the redox potential (see for example ref. 32 and 33). Reduction may be performed by doping $\mathrm{H}_{2}$ or metals e.g. $\mathrm{Mg}$ in the molten salt. The effect of redox in the molten salt may be modelled as performed earlier e.g. ref. 34. During burnup, the $\mathrm{U}$ in $\mathrm{UCl}_{3}$ is substituted by fission products and the remaining $3 \mathrm{Cl}^{-}$modifies the redox. ${ }^{35}$ The thermodynamic properties of fission products need to be calculated by modelling. The iodine redox states $(\mathrm{I}(-\mathrm{I}), \mathrm{I}(0)$ or $\mathrm{I}(\mathrm{I}))$ and the species in $\mathrm{M}-\mathrm{U}^{3 / 4+}-\mathrm{Cl}$ are subject to reactions such as:

$$
\begin{gathered}
\mathrm{I}^{0}(\mathrm{M}-\mathrm{U}-\mathrm{Cl})+\mathrm{U}^{3+}(\mathrm{M}-\mathrm{U}-\mathrm{Cl}) \Leftrightarrow \mathrm{I}^{-}(\mathrm{M}-\mathrm{U}-\mathrm{Cl})+\mathrm{U}^{4+}(\mathrm{M}-\mathrm{U}-\mathrm{Cl}) \\
\mathrm{I}^{0}(\mathrm{M}-\mathrm{U}-\mathrm{Cl}) \Leftrightarrow \mathrm{I}(\mathrm{g}) \\
\mathrm{Xe}^{0}(\mathrm{M}-\mathrm{U}-\mathrm{Cl}) \Leftrightarrow \mathrm{Xe}(\mathrm{g})
\end{gathered}
$$

Along with phase changes, the local distribution of $I$ is also linked to the mobility or diffusion of I in the liquid fuel. ${ }^{36,37}$ The combination of thermodynamic modelling will help understand the impact of these factors on the distribution of I in the liquid fuel.

The reprocessing of non-volatile fission products can be performed in-line by precipitation and filtration of insolubles and by electro-refining.

A MSR offers high burn-up, breeding and improvement of neutron economy thanks to the potential elimination of fission products by volatilisation ${ }^{38}$ or electrolysis ${ }^{39}$ and for the MSFR, the consumption of actinides. Under these conditions the consumption of uranium is reduced by at least a factor of 20 in a thermal MSR and 200 in a fast MSR.

For economic and ecological reasons, small modular MSRs (SM-MS-R) are suggested. The design of the various components of the system must be optimised. A multi-modular system includes a central part with a core and primary loop and systems to optimise breeding and extraction of the volatile fission products.

The secondary loop coolant allows transfer of energy from the primary to the turbine. Other modules of the SM-MS-R system include a third cooling loop consisting of a classical heat exchanger using cold water as the cold source (seawater is suggested in this combined approach). An additional container includes a waste management unit with a related vessel. A fluid waste management module is foreseen in which standard nuclear waste management is performed. It includes absorbers that collect the $\mathrm{Xe}, \mathrm{Kr}$ and I isotopes. At the end of its life the core/ primary molten salt can be collected in a catcher in a waste 
package ingot and could be directly disposed. The core and primary could be refilled with fresh salt components. The SM-MS$\mathrm{R}$ could be restarted finally with the input of fresh fissile salt.

Fig. 2 shows the various modules of the proposed version of the small modular-molten salt reactor adapted to ${ }^{238} \mathrm{U}$ breeding in ${ }^{239} \mathrm{Pu}$. Separation of fissile and fertile molten salts in a decay tank is foreseen. The reactor itself is a ${ }^{239} \mathrm{Pu}$ reactor in which the primary loop includes a heat exchanger. In the primary loop one also finds a reprocessing unit combined with a refuelling unit. The reprocessing unit is a simple degassing captor that allows fission gases to be purged out. The refuelling unit allows fresh plutonium to be reloaded in the fissile primary loop. The main issue at this level is to couple the decay tank and the refuelling unit. It is anticipated that ${ }^{239} \mathrm{U}$ shall be radiochemically separated and fully decayed into ${ }^{239} \mathrm{~Np}$. However, the decay of ${ }^{239} \mathrm{~Np}$ into ${ }^{239} \mathrm{Pu}$ requires several days during which the $\mathrm{U}$ system has to rely on the fissile reactor loop prior to first refuelling the fissile loop with fresh plutonium. It would consequently be suggested that the refuelling would work intermittently with periods of at least 3 days of decay prior to refuelling. The other option would be an actinide separation in the decay tank but this would be difficult to operate in-line.

For the fast MSR, the challenge is also at the beginning of fuel life, the initiation of the reaction. The chain reaction could be initiated by approaching externally a neutron source $e . g$. an actinide source $($ e.g. $\mathrm{Cm})$ or by spiking in the molten salt the required amounts of fissile isotopes.

In all cases, molten salt composition, core volume and geometry, primary loop geometry, and molten salt flow rate have to be calculated together with secondary and ternary loop characteristics. Their adaptation to power production has to be studied in an analytical way.

For both thermal and fast MSRs, designs have to be adapted with the local requirement concerning nuclear waste management.
Nuclear waste management of the volatile products trapped during operation requires specific absorbers. Irreversible absorption of the fission products is required together with the preparation of the final waste package for the geological repository.

For the spent fuel, MS samples could be collected from the core - the primary system in the auxiliary container, forming ingots at the end of its life.

\section{Discussion and proposed protocol}

Today, nuclear energy conversion is still based on heat production, using steam turbines with condensation using a cold source. The cold source is linked to a heat exchanger using cold water, balancing the energy difference between turbine heat and electrical energy produced by the coupled generator. For a renewable nuclear fuel cycle, the use of seawater as the cooling source has to be promoted. To run in a sustainable way the conversion requires also parsimonious utilization of uranium. The loaded uranium must be produced by recovering it from seawater used as the reactor cooling source. For a $1 \mathrm{GW}$ MSR running around $700{ }^{\circ} \mathrm{C}$, the requirement of a nuclear power plant to run the condenser below the turbine would be $2.1 \times 10^{9}$ tons of seawater per year. This seawater has to be filtered prior to passing through a heat exchanger contributing to the collection of plastics in seawater. A maximum temperature increase of $10^{\circ} \mathrm{C}$ of the water after heat exchange is currently the rule and 7 tons of natural uranium per year are anticipated to be extractable. Utilisation of a specific biomass absorber is required to extract pumped seawater uranium over weeks in pounds/pools downstream from the reactor. Each absorber (4 kg sorbing $400 \mathrm{mg} \mathrm{U}$ and other transition metals e.g. V, Mo, etc.) would be set in a $20 \mathrm{~cm}$ $\times 20 \mathrm{~cm} \times 10 \mathrm{~cm}$ bag dipping in a pound/pool of $250 \mathrm{~m} \times 250$ $\mathrm{m}$, a total of $8 \times 10^{7}$ bags made of (U non-sorbing) cellulose.

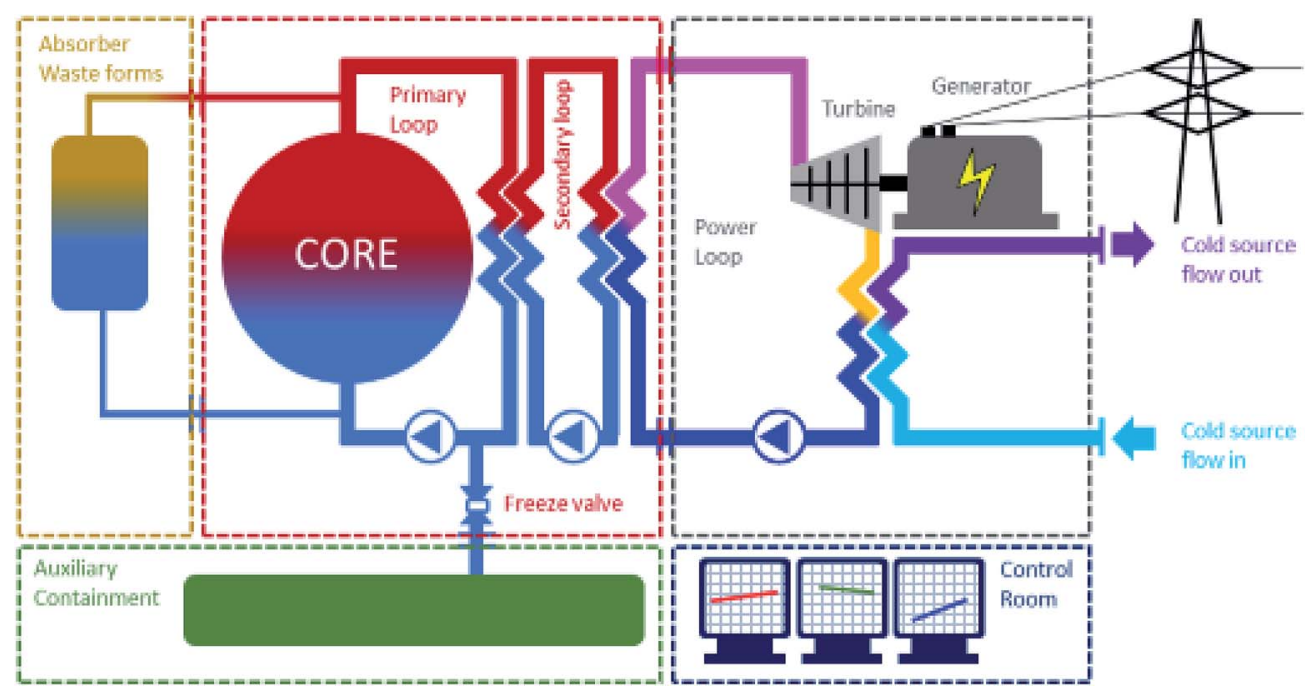

Fig. 2 SM-MS-R the modular concept. 1st module/container: core, primary and secondary. 2nd module/container: ternary, turbine/generator and cooling loop. 3rd module/container: waste management unit. 4th module/container: containment/accident MS catcher. 5th module/ container: control room. 
Since the water is rejected in the sea, it is mandatory that the processes operate in an environmentally friendly way. The reinjected seawater plume must be oriented in a way to avoid mixing with the input seawater to separate in the local stream the depleted water from the input water.

The sorbed biomass must be dried and burned in a carbon neutral way, converting the biomass into heat and then into electricity. The ash is then collected and treated for the production of $\mathrm{UCl}_{4}$. The nuclear fuel production must be performed in an optimal way using $\mathrm{U}_{3} \mathrm{O}_{8}$ and ash residues as starting materials. Its conversion to uranium tetrachloride is made using $\mathrm{C}^{37} \mathrm{Cl}_{4}$ around $500{ }^{\circ} \mathrm{C}$. The purified $\mathrm{U}^{37} \mathrm{Cl}_{4}$ is obtained by sublimation. It is dissolved in a molten salt prior to nuclear initiation using a fissile source. The energy produced for $1 \mathrm{GW}$ is obtained by burning 7 tons of uranium over a year. This corresponds to the amount of uranium present in the $2.1 \times 10^{9}$ tons of seawater used to cool down the reactor over a year. Fig. 3 depicts the processes required to run the nuclear fuel cycle though a MSR in a renewable way.

The nuclear waste impact is also a key issue. Fast reactors are known for their optimal low ratios of nuclear waste amount for a fixed annual power. Actually, the potential of fission product recycling is very limited. Recently, Bourg and Poinssot (2017) ${ }^{\mathbf{4 0}}$ investigated the potential of mining critical raw materials from fission products. They showed that the potential of reutilisation of fission products below the exemption limit after 50 years of cooling time is very limited. However, some radioactive fission products such as ${ }^{99} \mathrm{Tc}$ could be specifically separated for medical applications such as radio-immuno-assays. The potential of the production of specific Xe radioisotopes for medical applications, such as ${ }^{129} \mathrm{Xe}$ used in lung imaging studies ${ }^{41}$ and ${ }^{133} \mathrm{Xe}$ used for brain imaging, ${ }^{42}$ must also be noted.

The impact of the MSR on the correction of the energy load on the grid is the next issue. A molten salt reactor is a liquid fuel reactor where, in the classical concept, the fuel is also the coolant. In this configuration the liquid fuel reactor can operate in fast transient mode such as that required when coupling a classical renewable and nuclear reactor on the grid. This was investigated by Dodson and Mccan $(2013)^{43}$ for the thorium molten salt reactor and could also be the case for the uranium molten salt reactor. Clearly with the exception of metallic fuels all ceramic fuels are quite brittle and do not undergo transients such as those required to recover from wind turbines and photovoltaic cell production shortages. The photovoltaic transient may be of the order of $75 \%$ difference between full production for panel full illumination and reduction due to the clouding or shadowing of the panel in $30 \mathrm{~s}$. An increase of production yield must be anticipated to meet the energy demand. This can be performed with the MSR by varying the molten salt flow rate.

The global impact of the renewable fuel cycle on the environment must be extended to the whole MSR park. A uranium extraction rate of 1000 tons per year from the sea would not modify significantly the equilibrium concentration of uranium in the oceans i.e. $3.3 \mathrm{ppb}$. This constant concentration results from an input of $10 \mathrm{kt}$ of $\mathrm{U}$ per year by river water and its scavenging on the sea floor from the $1.37 \times 10^{18}$ tons of water in the oceans corresponding to a total amount of tons of uranium. Since the volume of water in the sea is immense the extraction over the next 1000 years would not significantly affect the total uranium amount in the sea: $\sim 10^{12} \mathrm{~kg}$. The strict renewable concept would correspond to a $1000 \mathrm{t}$ uranium consumption which corresponds to 150 fast MSR units of $1 \mathrm{GW}$ each. For a renewable uranium extraction, the use of a specific biomass material is suggested to fulfill the sorption of uranium and subsequently other transition metals ( $\mathrm{V}$ and Mo) that could be extracted consequently. The annual consumption rate of a reactor park would even remain smaller than the natural uranium recovery rate by scavenging in seawater.

\section{Conclusion and recommendations}

The suggested conditions required to fulfill a nuclear renewable fuel cycle combine processes from the front end of the fuel cycle to the fuel production and the energy conversion using molten salt fast reactors.

Extraction of uranium from seawater has been studied in various countries of the world. This extraction should be carried

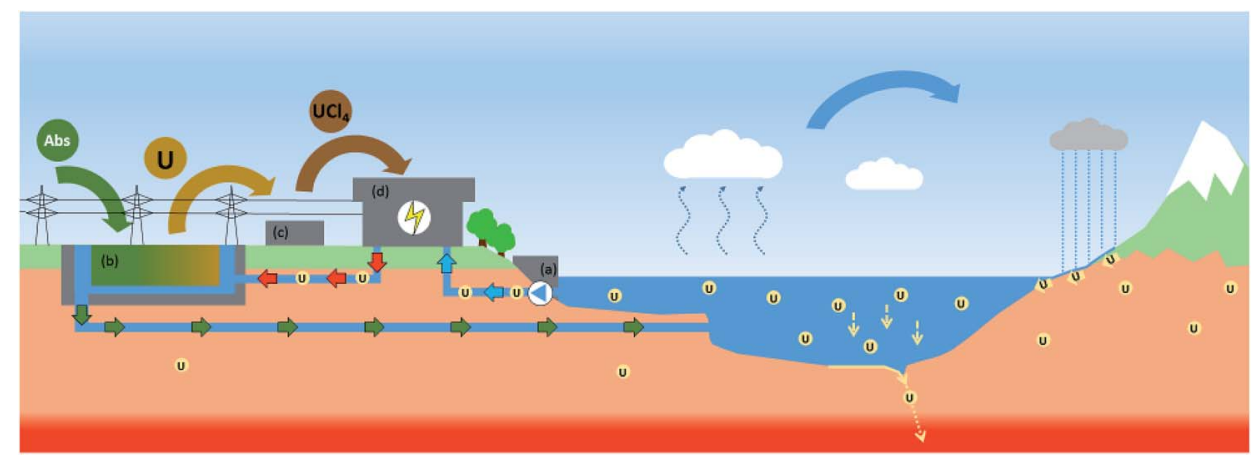

Fig. 3 Schematic view of the combination of processes including uranium extraction from seawater and burning in a molten salt fast reactor. Details of (a) cooling water pumping, (b) absorption on biomass in a pound downstream from the molten salt fast nuclear reactor, (c) biomass uranium recovery and fuel production plant and (d) the molten salt fast reactor needed for burning the recovered uranium in a renewable way with consumption rate compared to the recharge of uranium in the sea by rivers. 
out parsimoniously. An extraction rate of $10^{3}$ tons of $U$ per year for a MSR park of 500 MSRs over centuries would not modify significantly the equilibrium uranium concentration $(3.3 \mathrm{ppb})$ in the oceans, resulting from the input of $10^{4}$ tons of $U$ per year by river waters and its scavenging on the sea floor from the 1.37 $\times 10^{18}$ tons of water in the oceans.

The extraction of uranium from seawater is being studied on the laboratory scale. On the industrial scale it should be carried out utilising specific biowaste absorbents for performing the absorption of uranium from the rejected seawater from dedicated nuclear power plants' cooling seawater, in large pounds/ pools where the sorbent is in contact with seawater over several weeks. For a renewable uranium extraction, the use of a specific biomass material is suggested to fulfill the sorption of uranium and subsequently other transition metals with a loading on the biomass of around $100 \mathrm{mg}$ per $\mathrm{kg}$. At equilibrium, the loaded material shall be removed from the pound, dried, burned $\left(\mathrm{CO}_{2}\right.$ neutral $)$ with heat conversion into electricity.

The subsequent ashes are collected and treated by applying the classical hydrometallurgical route to produce $\mathrm{UO}_{2}$ then $\mathrm{UCl}_{4}$.

The uranium 'burning' with a molten salt fast reactor helps to optimize the energy conversion by burning all actinide isotopes with an excellent yield for producing a maximum amount of thermal energy from fission and converting it into electricity. This can be reached by reducing the moderation and the fission product concentration in the liquid fuel/ coolant. This can be achieved by using a maximum amount of actinides and a minimum amount of alkaline/earth alkaline elements yielding a harder neutron spectrum. Under these optimal conditions the consumption of natural uranium would be 7 tons per year and per gigawatt (GW) of produced electricity.

The fuel utilized in molten salt fast reactors is in the form of $\mathrm{Na} / \mathrm{Rb} / \mathrm{Mg}-\mathrm{U}-\mathrm{Pu}-{ }^{37} \mathrm{Cl}$, the choice of ${ }^{37} \mathrm{Cl}^{-}$being dictated by safety and neutronic reasons. The addition of Pu may be required to enhance the power at the beginning of its life.

During operation, the generation of fission products poisons the core of the reactor and the primary. However, some unsuitable isotopes such as ${ }^{135} \mathrm{Xe}$, or its parent nuclide ${ }^{135} \mathrm{I}$, could be discarded from the core/loop by various strategies. A maximum elimination is required and these gaseous/volatile phases need to be studied using a thermodynamics approach to better carry out their elimination. They also need to be absorbed and fixed (e.g. by specific sorption) onto waste matrices for disposal.

Coupling of uranium extraction from the sea and its optimal utilization in a molten salt fast reactor should allow nuclear energy to gain the label renewable. In addition the amount of seawater used by nuclear power plants to cool the last cooling fluid loop and the turbine would be $\sim 2 \times 10^{9}$ tons per year, corresponding to 7 tons of natural uranium per year. This practice justifies the label renewable.

\section{Conflicts of interest}

There are no conflicts to declare.

\section{References}

1 J. S. Henning, Uranium and thorium resource assessment, Encyclopedia of Energy, 2004, pp. 279-98.

2 NEA and IAEA, Uranium 2016 - resource, production and demand, OECD publishing, 2016, p. 548, available from http:/www.oecd-nea.org/ndd/pubs/2016/7301-uranium2016.pdf.

3 G. M. Mudd, The environmental sustainability of mining in Australia: key megatrends and looming constraints, Resour. Pol., 2010, 35, 98-115.

4 M. Tamada, N. Seko, N. Kasai and T. Shimizu, Cost Estimation of Uranium Recovery from Seawater with System of Braid type Adsorbent, J. At. Energy Soc. Jpn., 2006, 5, 358-363.

5 K. Hara, T. Nishimoto, S. Fujiwara, T. Fujii, Y. Hidaka and H. Okabe, Attempts at capturing ppb-level elements from sea water with hydrogels, Prog. Nucl. Energy, 2016, 92, 228233.

6 C. Liu, P.-C. Hsu, J. Xie, J. Zhao, T. Wu, H. Wang, S. Chu and Y. Cui, A half-wave rectified alternating current electrochemical method for uranium extraction from seawater, Nat. Energy, 2017, 2, 17007.

7 L. Chen, Z. Bai, L. Zhu, L. Zhang, Y. Cai, Y. Li, W. Liu, Y. Wang, L. Chen, J. Diwu, J. Wang, Z. Chai and S. Wang, Ultrafast and Efficient Ch.Extraction of Uranium from Seawater Using an Amidoxime Appended Metal-Organic Framework, ACS Appl. Mater. Interfaces, 2017, 9(38), 3244632451.

8 S. Kung, Uranium in seawater, Ind. Eng. Chem. Res., 2016, 55, 4101-4361.

9 K. Dungan, G. Butler, F. R. Livens and L. M. Warren, Uranium from seawater - Infinite resource or improbable aspiration?, Prog. Nucl. Energy, 2017, 99, 81-85.

10 C. Degueldre, Uranium as a renewable for nuclear energy, Prog. Nucl. Energy, 2017, 94, 174-186.

11 C. Degueldre, Retention of redox sensitive elements in aquifers-the case of neptunium, J. Environ. Radioact., 1997, 34, 211-214.

12 M. R. Palmer and J. M. Edmond, Uranium in river water, Geochim. Cosmochim. Acta, 1993, 57, 4947-4955.

13 O. D. Maslov, S. Tserenpil, N. Norov, M. V. Gustova, M. F. Filipov, A. G. Belov, M. Altangerel and N. Enhbat, Uranium recovery from coal ash dumps of Mongolia, Solid Fuel Chem., 2010, 44, 433-438.

14 G. Lofrano, M. Grassi and M. Notarnicola, Characteristics and adsorption capacities of low-cost sorbents for wastewater treatment: a review, Sustainable Mater. Technol., 2016, 9, 10-40.

15 C. Degueldre, H.-J. Ulrich and H. Silby, Sorption of Am onto montmorillonite, illite and hematite colloids, Radiochim. Acta, 1994, 65, 173-179.

16 B. B. Mathew, M. Jaishankar, V. G. Biju and K. N. Beeregowda, Role of Bioadsorbents in Reducing Toxic Metals, J. Toxicol., 2016, 2016, 4369604. 
17 J. W. Ball and D. K. Nordstrom, User's manual for WATEQ4F, with revised thermodynamic data base and test cases for calculating speciation of major, trace, and redox elements in natural waters: U.S. Geological Survey Open-File Report 91183, 1991.

18 S. C. Gondhalekar and S. R. Shukla, Equilibrium and kinetics study of uranium(VI) from aqueous solution by Citrus limetta peels, J. Radioanal. Nucl. Chem., 2014, 302, 451-457.

19 B. Satari and K. Karimi, Citrus processing wastes: Environmental impacts, recent advances, and future perspectives in total valorization, Resour., Conserv. Recycl., 2018, 129, 153-167.

20 T. Sakaguchi, A. Nakajima and T. Horikoshi, Absorption of uranium from sea water by biological substances, Nippon Nogeikagaku Kaishi, 1979, 53, 149-156.

21 A. Nakajima and T. Sakaguchi, Adsorption of Uranium by Vegetable Crude Drugs, Agric. Biol. Chem., 1989, 53, 28532859.

22 T. Sakagushi and A. Nakajima, Recovery of uranium from seawater by immobilized tannin, Sep. Sci. Technol., 1987, 22, 1609-1623.

23 K. Ashworth, O. Wild and C. N. Hewitt, Impact of biofuel cultivation on mortality and crop yield, Nat. Clim. Change, 2013, 3, 492-496.

24 J. Serp, M. Allibert, O. Beně̌, S. Delpech, O. Feynberg, V. Ghetta, D. Heuer, D. Holcomb and V. Ignatiev, The molten salt reactor (MSR) in generation IV: Overview and perspectives, Prog. Nucl. Energy, 2014, 77, 308-319.

25 M. V. Smirnov, I. V. Korzun and V. A. Olegnikeva, Hydrolysis of molten alkali chlorides, bromides and iodides, Electrochim. Acta, 1988, 33, 781-788.

26 M. J. Eades, E. S. Chaleff, P. F. Venneri and T. Blue, The influence of Xe-135m on steady-state xenon worth in thermal molten salt reactors, Prog. Nucl. Energy, 2016, 93, 397-405.

27 J. Wu, C. Guo, X. Cai, C. Yu and J. Chen, Flow effect on 135I and 135Xe evolution behavior in a molten salt reactor, $\mathrm{Nucl}$. Eng. Des., 2017, 314, 318-325.

28 D. S. Akerib, H. M. Araújo, X. Bai, A. J. Bailey and C. Zhang, Chromatographic separation of radioactive noble gases from xenon, Astropart. Phys., 2018, 97, 80-87.

29 R. Dawson and G. J. Kelsall, Recovery of platinum group metals from secondary materials: I palladium dissolution in iodide solutions, J. Appl. Electrochem., 2007, 37, 3, DOI: 10.1007/s10800-006-9218-8.

30 I. Scott, Gaseous and volatile fission product release from moltensalt nuclear reactor, Proceedings Thorium Energy Conference 2015, ThEC15, Mumbai, India, Oct. 19-22, 2015.
31 R. Dawson, Electrochemical Recovery of platinum and Palladium from Alumina Supported Catalysts, PhD thesis, Imperial College, London, UK, 2006.

32 T. Nagai, A. Uehara, T. Fujii, O. Shirai, N. Sato and H. Yamana, Redox equilibrium of $\mathrm{U} 4+/ \mathrm{U} 3+$ in Molten $\mathrm{NaCl}-2 \mathrm{CsCl}$ by UV-Vis and cyclic voltammetry, J. Nucl. Sci. Technol., 2005, 42, 1025-1031.

33 T. Nagai, A. Uehara, T. Fujii, O. Shirai, N. Sato and H. Yamana, Electrochemical behaviour and electronic absorption spectra of uranium trivalent in molten LiClCsCl mixtures, J. Nucl. Mater., 2011, 414, 226-231.

34 Y.-J. Cho, H.-C. Yang, H.-C. Eun, E.-H. Kim and I.-T. Kim, Characteristics of Oxidation Reaction of Rare-earth Chlorides for Precipitation in LiCl-KCl Molten Salt by Oxygen Sparging, J. Nucl. Sci. Technol., 2006, 43, 12801286.

35 V. Singh, M. R. Lish, O. Chvála and B. R. Upadhyaya, Dynamics and control of molten-salt breeder reactor, $\mathrm{Nucl}$. Eng. Technol., 2017, 49, 887-895.

36 M. V. Smirnov, I. V. Chebykia and L. A. Tsiovkina, Thermodynamic properties of sodium and potassium in molten chlorides, bromides and iodides, Electrochim. Acta, 1981, 26, 1275-1288.

37 M. V. Smirnov and O. Tkacheva, Interaction of oxygen with molten alkali chlorides, Electrochim. Acta, 1992, 37, 26812690.

38 E. L. Compere, S. S. Kirslis, E. G. Bohlmann, F. F. Blankenship and W. R. Grimes, Fission product behaviour in the molten salt reactor experiment, ORNL-4865, 1975, p. 143.

39 V. M. Oversby, C. C. McPheeters, C. Degueldre and J. M. Paratte, Control of civilian plutonium inventories using burning in a non-fertile fuel, J. Nucl. Mater., 1997, 245, 17-26.

$40 \mathrm{~S}$. Bourg and C. Poinssot, Could spent nuclear fuel be considered as a non conventional mine of critical row material, Prog. Nucl. Energy, 2017, 94, 222-228.

41 F. W. Hersman, I. C. Ruset, S. Ketel, I. Muradian and S. Patz, Large Production System for Hyperpolarized 129Xe for Human Lung Imaging Studies, Acad. Radiol., 2008, 15, 683-692.

42 R. Wirestam, E. Ryding, A. Lindgren, B. Geijer and F. Ståhlberg, Absolute cerebral blood flow measured by dynamic susceptibility contrast MRI: a direct comparison with Xe-133 SPECT, Magn. Reson. Mater. Phys., Biol. Med., 2000, 11, 96-103.

43 A. M. Dodson and R. A. McCann, Investigation of thermal feedback design for improved load following capability of thorium molten salt reactor, Proc. IEEE 2013 green technology, pp. 215-219, DOI: 10.1109/Green Technol. 2013 40 . 